\title{
Fluorescence properties of 3- and 4-trifluoroacetylamino-1,8- naphthalimides: Solvent-controlled switching of fluorescence color and response to metal-cations
}

\author{
Hideki Okamoto,* Kyosuke Satake, and Masaru Kimura \\ Department of Chemistry, The Graduate School of Natural Science and Technology, Okayama \\ University, Tsushima-Naka 3-1-1, Okayama 700-8530, Japan \\ E-mail: hokamoto@,cc.okayama-u.ac.jp
}

Dedicated to Professor Waldemar Adam on the occasion of his 70th birthday

\begin{abstract}
The effects of solvents and metal cations on the fluorescence spectra of 3- (1) and 4- (2) trifluoroacetylamino-1,8-naphthalimides were investigated. In $\mathrm{MeCN}$, these naphthalimides displayed a violet $\sim$ blue fluorescence based on their neutral amide form $(\mathbf{1}, \mathbf{2})$. Whereas in DMSO, they gave off a yellow $\sim$ orange emission due to their amide anions $\left(\mathbf{1}^{-}, \mathbf{2}^{-}\right) . \mathrm{In} \mathrm{MeOH}$, naphthalimide 2 emitted a dual fluorescence $\left(\lambda_{\mathrm{FL}} 436\right.$ and $\left.556 \mathrm{~nm}\right)$ to display a white luminescence. Naphthalimides 1, $\mathbf{2}$ are essentially insensitive to metal cations in their neutral amide form. In contrast, the fluorescence of the amide anions $\mathbf{1}^{-}, \mathbf{2}^{-}$was quenched by metal cations. The efficiency of the quenching correlated with the Lewis acidity of the metal cations; a stronger Lewis acid tended to display a more effective fluorescence quenching. Therefore, the fluorescence color and the sensitivity to metal cations of the naphthalimides were effectively switched by the solvent.
\end{abstract}

Keywords: Fluorescence, 1,8-naphthalimide, switching, solvent effects, metal cation, white fluorescence

\section{Introduction}

A number of chemosensors has been developed by the combination of the host functions with chromophores, ${ }^{1}$ fluorophores, ${ }^{2}$ or chemiluminophores. ${ }^{3}$ Most such conventional chemosensors display a response to a single specific analyte. Recently, fluorometric and colorimetric probes responding to both ionic species and environmental conditions have been reported. ${ }^{4-6}$ Such a molecular design would be applicable for the construction of a multicolor molecular probe with a 
simplified chemical structure ${ }^{6}$ because the incorporated chromophore serves as a sensor by itself of environmental factors (solvent polarity, hydrogen bonding, $\mathrm{pH}$, etc.). ${ }^{7}$

4-Amino-1,8-naphthalimide has been known to display a significant solvatofluorochromism due to its intramolecular charge transfer (ICT) transition and has been used as a probe for microscopic polarity. ${ }^{8}$ A 4-acetylamino derivative of 1,8-naphthalimide has been reported as an efficient fluorophore. ${ }^{9}$ In addition to such fundamental studies on the 4amino-1,8-naphthalimides, applications to chemosensors using the chromophore have recently appeared: ${ }^{10-12}$ The 4-amide derivatives of 1,8-naphthalimide, e.g. 4-benzoylamide ${ }^{10}$ and a urea derivative, ${ }^{11}$ displayed a response to the fluoride anion in $\mathrm{MeCN}$ because their acidic amide proton is abstracted by the basic fluoride anion. As the formation of the amide anion resulted in modification of both the absorption and emission spectra, these amide- and urea-modified 4amino-1,8-naphthaimides serve as fluoride sensors in an organic medium. ${ }^{10-12}$ Therefore, 4amino-1,8-naphthalimide would be a promising chromophore for the construction of a novel functionalized fluorophore.

In the present study, the amino group in 3- and 4-amino-1,8-naphthalimides was modified as trifluoroacetamide (1 and $\mathbf{2}$, Scheme 1) to facilitate the dissociation of their amide protons affording amide anions $\mathbf{1}^{-}, \mathbf{2}$. We have anticipated that we could control the acid-base equilibrium by regulation of the basicity or hydrogen-bonding character of the solvent (Scheme 1). The amide anions $\left(\mathbf{1}^{-}, \mathbf{2}^{-}\right)$would display different spectral patterns and responses to cationic species than those of the corresponding conjugate acids (1 and 2). Although the amide anions (1', $\left.\mathbf{2}^{-}\right)$are expected to display higher sensitivity to cationic species than the neutral amide forms (1, 2), their spectral features have not been revealed in the presence of cations. Herein, we would like to describe the role of the solvents on the fluorescent properties and the response to metal cations of the modified naphthalimides $\mathbf{1}$ and $\mathbf{2}$.

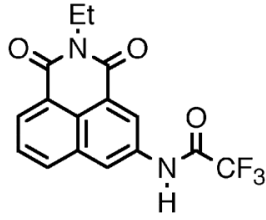

1

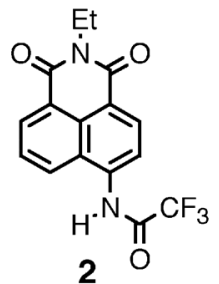

2

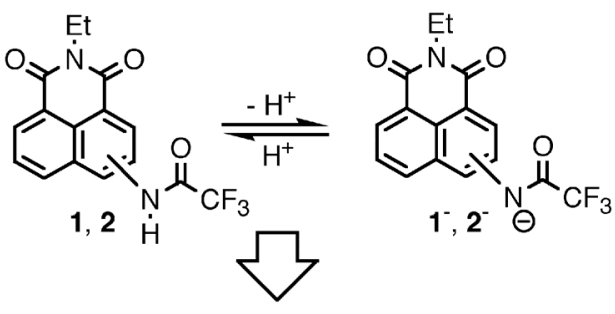

Modification of $\left\{\begin{array}{l}\text { spectral properties } \\ \text { response to cations }\end{array}\right.$

Scheme 1. The structures of the naphthalimides $\mathbf{1}$ and $\mathbf{2}$, and the concept of modification of their properties by a solvent-controlled acid-base equilibrium. 


\section{Results and Discussion}

Absorption spectra. Figure 1a shows the absorption spectra of the naphthalimides $\mathbf{1}$ in several solvents. In $\mathrm{MeCN}$ and $\mathrm{MeOH}$, naphthalimide 1 showed an absorption band $\left(\lambda_{\max } \sim 335 \mathrm{~nm}\right)$ with a shoulder at $370 \mathrm{~nm}$ corresponding to the naphthalimide chromophore (Figure 1a). ${ }^{9,10}$ In contrast, in DMSO, a red-shifted absorption band appeared at $\lambda_{\max } 431 \mathrm{~nm}$. As we have expected from the present molecular design, the red-shifted absorption band was deduced to be assignable to the amide-anion species of the naphthalimide $\mathbf{1}$ (Scheme 1 ). ${ }^{10}$ In order to reveal the nature of this band, the absorption spectra of the naphthalimide 1 were measured in the presence of the base. Upon the addition of DBU (1,8-diazabicyclo[5.4.0]undec-7-ene, 5 equiv.) to a solution of naphthalimide 1 in $\mathrm{MeCN}$, the red-shifted band, which was similar to that detected in DMSO, was observed at around $420 \mathrm{~nm}$ as shown in Figure 1b. The red-shifted absorption band was, thus, assigned to the amide-anion form of the naphthalimide, $\mathbf{1}^{\text {. }}$.
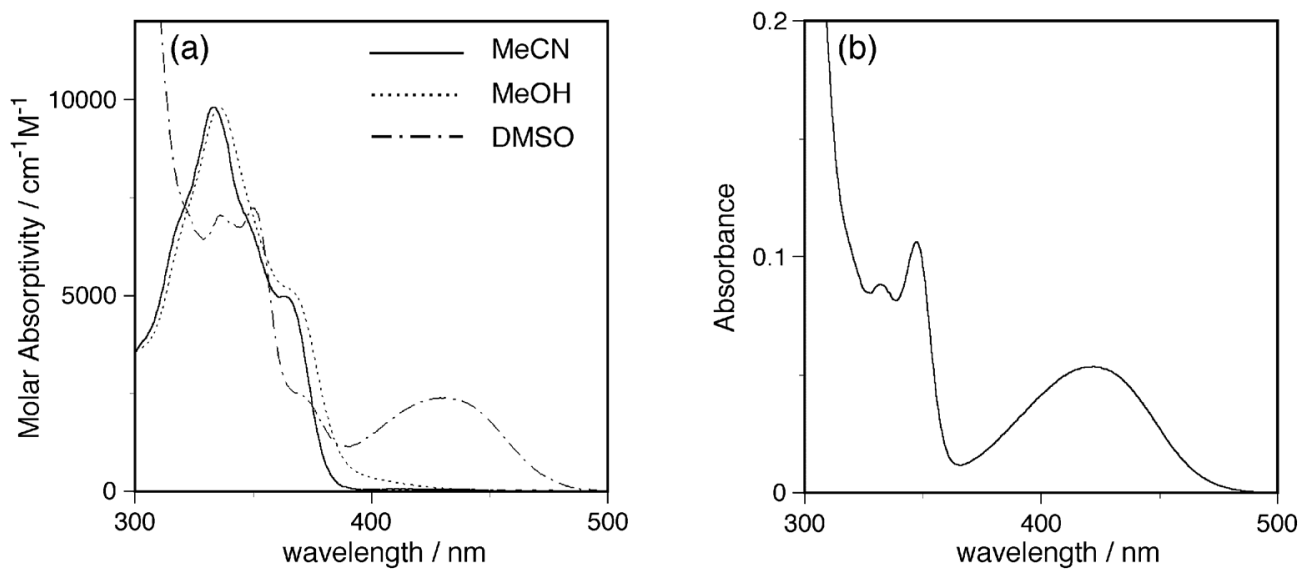

Figure 1. Electronic absorption spectra of naphthalimides 1 (a) in various solvents, and (b) in the presence of DBU (5 equiv.) in $\mathrm{MeCN}\left(1.3 \times 10^{-5} \mathrm{M}\right)$.

In the case of the naphthalimide 2 , an absorption band due to the 4-substituted naphthalimide chromophore $\left(\lambda_{\max } 334 \mathrm{~nm}\right)^{9}$ was observed in MeCN (Figure 2a). While in DMSO, a red-shifted band ( $\lambda_{\max } 442 \mathrm{~nm}$ ) was observed. As in the case of naphthalimide 1 , such a red-shifted absorption band was also detected upon the addition of DBU in MeCN (Figure 2b). The absorption band in DMSO was assigned to the amide-anion form 2 -

It has been shown that DMSO is a stronger electron-pair donor (Lewis base) than MeCN. ${ }^{13,14}$ Additionally, the strongly electron-withdrawing nature of the trifluoroacetyl group significantly enhanced the acidity of the amide proton. Therefore, it is concluded that the acidic amide proton of the naphthalimides $\mathbf{1}$ and $\mathbf{2}$ dissociated in DMSO affording their amide anions that display an absorption band in the longer wavelength region (Figures 1, 2). ${ }^{15}$ For a 4-ureasubstituted derivative of 1,8-naphthalimide, which has the same substructure as naphthalimide $\mathbf{2}$, 
such a red-shifted absorption band was not observed in DMSO. ${ }^{10,11}$ Thus the trifluoroacetyl group in the naphthalimides $\mathbf{1}$ and $\mathbf{2}$ plays an important role in the solvent-dependent spectral change.

In the absorption spectrum of naphthalimide 2 in $\mathrm{MeOH}$, an additional broad band was detected at around $400 \mathrm{~nm}$ (Figure 2a). The properties of this absorption band will be discussed in connection with the behavior of the pertinent band in the fluorescence spectra in the solvent (vide infra).
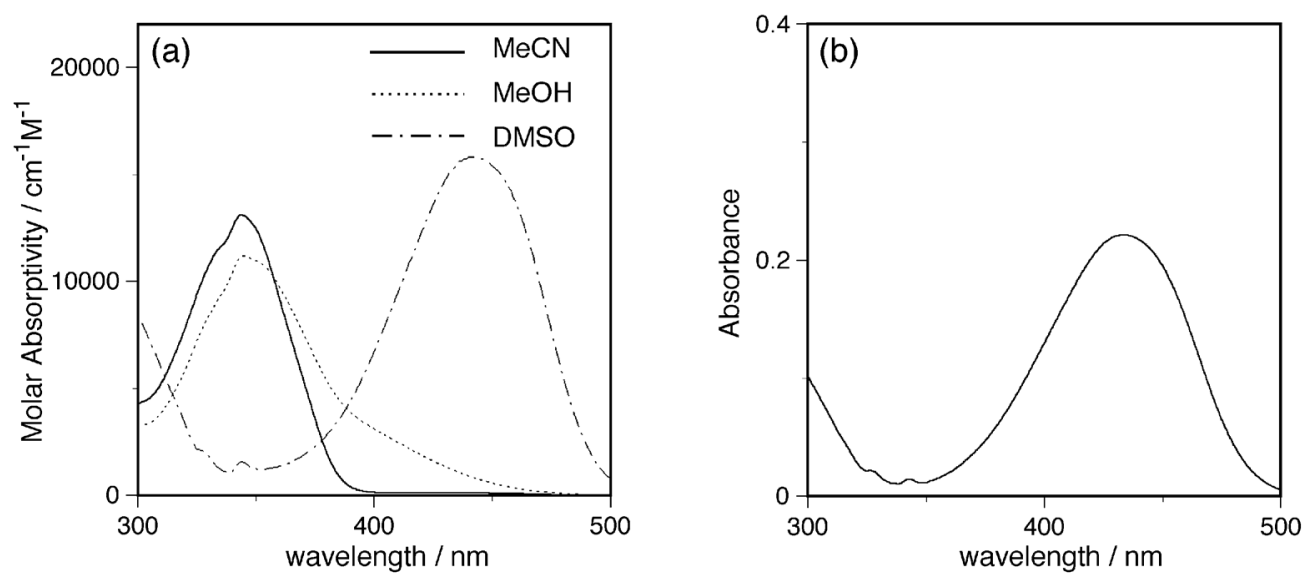

Figure 2. Electronic absorption spectra of naphthalimides 2 (a) in various solvents, and (b) in the presence of DBU (5 equiv.) in $\mathrm{MeCN}\left(1.3 \times 10^{-5} \mathrm{M}\right)$.

Fluorescence spectra. Upon photoexcitation, naphthalimide 1 produced a violet fluorescence $\left(\lambda_{\mathrm{FL}} 388 \mathrm{~nm}\right)$ in $\mathrm{MeCN}$ and $\mathrm{MeOH}$ as shown in Figure 3a. Whereas in DMSO, an orange emission ( $\lambda_{\mathrm{FL}} 575 \mathrm{~nm}$ ) was observed (Figure 3a). In the presence of DBU in MeCN, naphthalimide 1 displayed a red-shifted emission band which was similar to that observed in DMSO (Figure 3b). Thus, the orange emission was assigned to the amide anion 1'. These observations are consistent with the absorption behavior of naphthalimide 1 (Figure 1). The deprotonation of the amide moiety enhanced the electron-donating ability of the substituent and affected the ICT character from the amide part to the electron-withdrawing imide group to produce the red-shifted emission band. ${ }^{16}$

Figure $4 \mathrm{a}$ shows the fluorescence emission spectra of naphthalimide $\mathbf{2}$. Naphthalimide $\mathbf{2}$ displayed a blue fluorescence in $\mathrm{MeCN}\left(\lambda_{\mathrm{FL}} 418 \mathrm{~nm}\right)$ and a yellow emission in DMSO ( $\lambda_{\mathrm{FL}} 542$ $\mathrm{nm})$. The yellow emission was detected by the addition of DBU to a MeCN solution of the naphthalimide 2 (Figure 4b) similar to the case of naphthalimide 1. The red-shifted emission observed in DMSO is, thus, attributed to the enhanced ICT character due to the formation of the amide-anion species 2- These results indicate that one can effectively control the fluorescence color of the naphthalimides $\mathbf{1}$ and $\mathbf{2}$ by changing the Lewis basicity of the solvent, in other words, solvent-controlled switching of the fluorescence color is attained with the present system. 

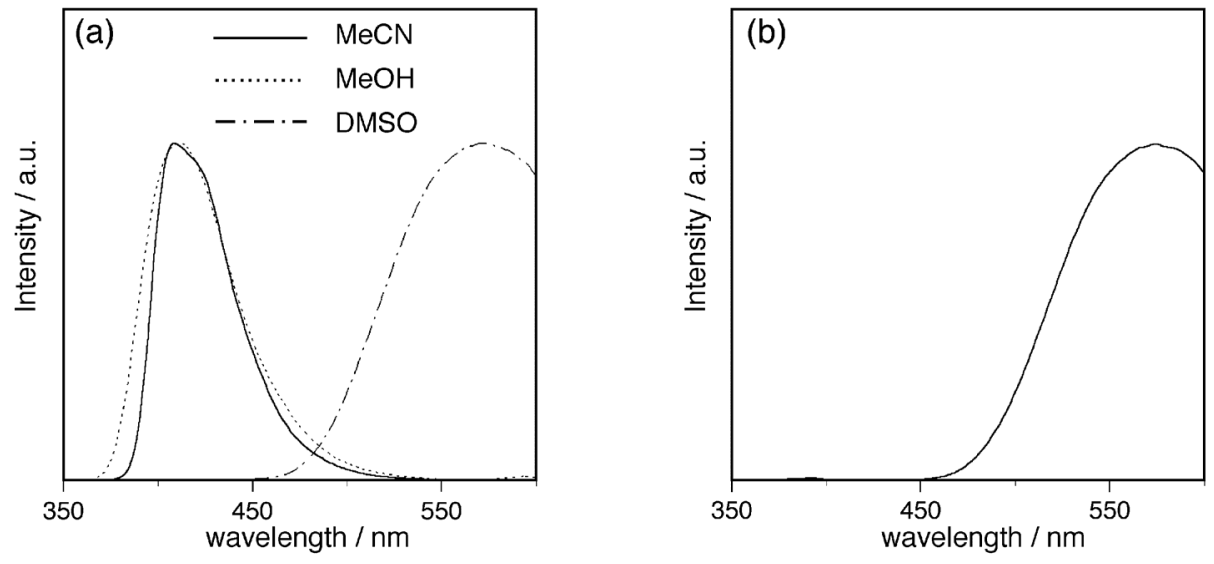

Figure 3. Normalized fluorescence emission spectra of naphthalimide $\mathbf{1}$ (a) in various solvents $\left(\lambda_{\text {ex }} 340 \mathrm{~nm}\right.$ ), and (b) in the presence of DBU (5 equiv.) in $\mathrm{MeCN}\left(\lambda_{\mathrm{ex}} 345 \mathrm{~nm}\right)$.
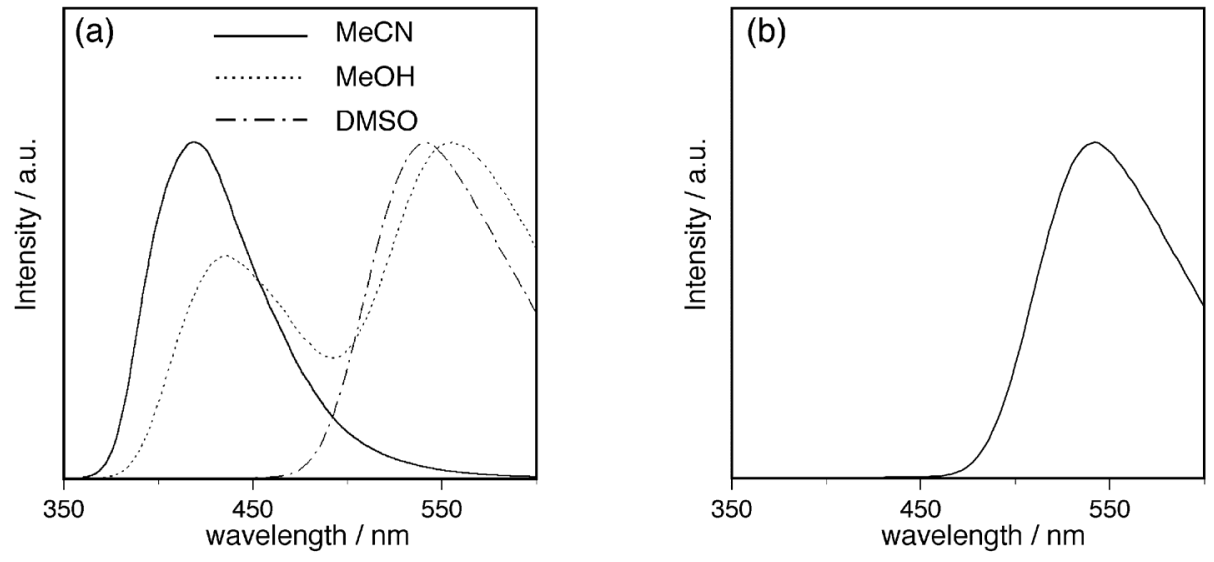

Figure 4. Normalized fluorescence emission spectra of naphthalimide $\mathbf{2}$ (a) in various solvents $\left(\lambda_{\text {ex }} 340 \mathrm{~nm}\right.$ ), and (b) in the presence of DBU (5 equiv.) in $\operatorname{MeCN}\left(\lambda_{\text {ex }} 375 \mathrm{~nm}\right)$.

The fluorescence of the naphthalimide 2 in $\mathrm{MeOH}$ showed two emission bands $\left(\lambda_{\mathrm{FL}} 436\right.$ and $556 \mathrm{~nm}$, Figure 4a). As already described, the absorption profile of naphthalimide 2 in $\mathrm{MeOH}$ is similar to that observed in $\mathrm{MeCN}$, but with an additional absorption band that overlapped at around $400 \mathrm{~nm}$ (cf. Figure 2a). It is probable that, in $\mathrm{MeOH}$, both the amide 2 and its anion 2 - coexist in equilibrium (Scheme 1), and due to these two species, the dual fluorescence was observed. This is also supported by the fact that the intensity of the absorption shoulder ( $400 \mathrm{~nm}$, cf. Figure $2 \mathrm{a})$ increased with the addition of a base $\left(\mathrm{Bu}_{4} \mathrm{NOH}\right)$ in $\mathrm{MeOH}$. Furthermore, in the fluorescence spectra, a decrease in the shorter-wavelength band $\left(\lambda_{\mathrm{FL}} 436 \mathrm{~nm}\right)$ and increase in the longer-wavelength one $\left(\lambda_{\mathrm{FL}} 556 \mathrm{~nm}\right)$ were simultaneously observed upon the addition of the base in $\mathrm{MeOH}$ (data not shown). 
Concerning the fluorescence properties of naphthalimide 2 , it is worth noting that because the dual fluorescence bands are spread over the entire visible region (Figure $4 \mathrm{a}$ ), the color of the emission is white as displayed in Figure 5. A white emission with a single-chromophoric molecule is quite rare, ${ }^{17}$ therefore, these emission profiles of naphthalimide 2 may be applicable as a new lighting source.

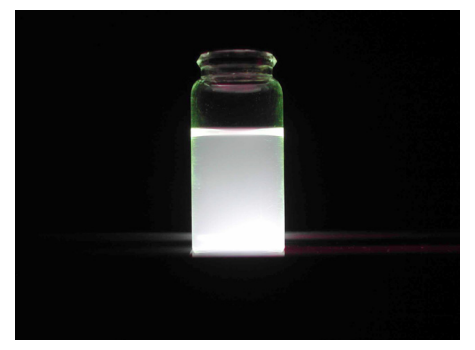

Figure 5. Color picture of the white fluorescence $\left(\lambda_{\text {ex }} 365 \mathrm{~nm}\right)$ of naphthalimide 2 in $\mathrm{MeOH}$.

Response toward metal cations. In order to reveal the sensitivity of the naphthalimides $\mathbf{1}, \mathbf{2}$ to cationic species, their absorption and fluorescence spectra were measured in the presence of metal cations. When the absorption and emission spectra of naphthalimides $\mathbf{1}$ and $\mathbf{2}$ were measured in $\mathrm{MeCN}$ by the addition of 10 equivalents of transition-metal salts, essentially no effect on the spectra was detected (data not shown). In contrast, in DMSO, their amide-anion bands (cf. Figures 1a, 2a) were significantly affected in the presence of metal cations.

Figure 6 a shows the absorption spectra of the naphthalimide 1 observed in the presence of 10 equivalents of metal cations (in DMSO). The corresponding changes in the fluorescence spectra, excited at the one of the apparent isosbestic points $(384 \mathrm{~nm})$, are illustrated in Figure $6 \mathrm{~b}$. The amide-anion emission band at $575 \mathrm{~nm}$ decreased with the addition of cations. The emission band of the amide anion $\mathbf{1}^{-}$was quenched by the metal cations and the efficiency of the quenching was parallel to that of the suppression of the amide-anion absorption band. Among the examined metal cations, the transition-metal cations effectively quenched the emission band: Ten equivalents of $\mathrm{Cu}^{2+}$ almost completely quenched the fluorescene. Alkaline and alkaline-earth metal cations displayed slight to moderate quenching effects. 

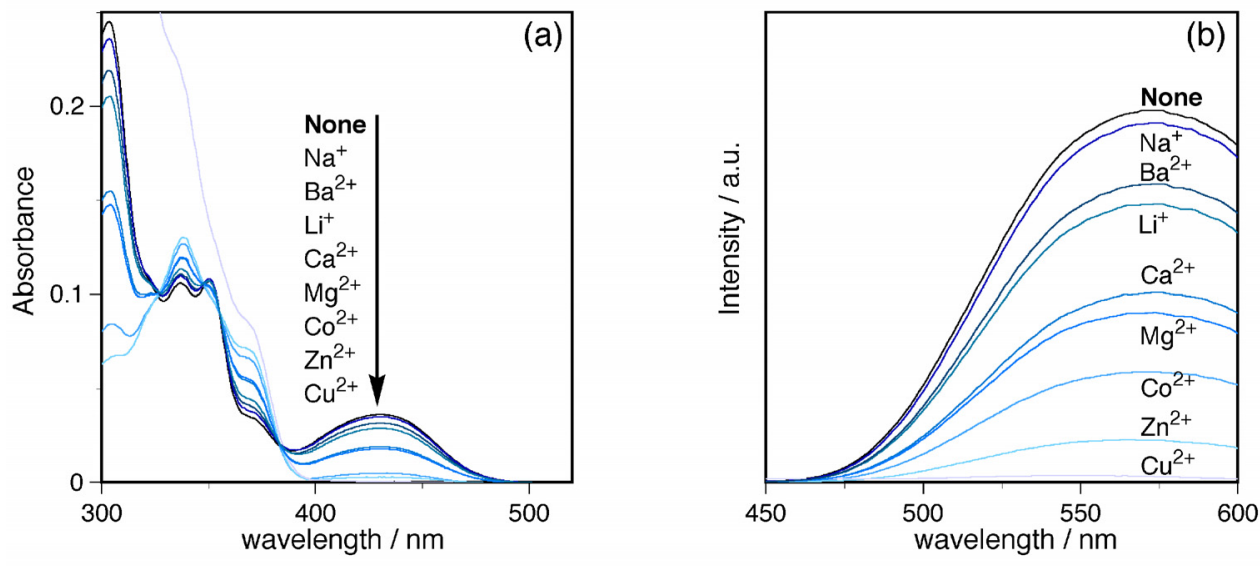

Figure 6. (a) Absorption and (b) fluorescence emission spectra $\left(\lambda_{\text {ex }} 384 \mathrm{~nm}\right)$ of naphthalimide 1 in the presence of metal cations (10 equiv.) in DMSO. In the absorption spectrum observed by addition of $\mathrm{Cu}^{2+}$, the absorption band of the metal cation overlapped in the shorter wavelength region $(<370 \mathrm{~nm})$.

Naphthalimide 2 also responded to metal cations in DMSO as shown in Figure 7. Transition-metal cations moderately reduced the intensity of the amide-anion absorption band (442 nm), while $\mathrm{Li}^{+}, \mathrm{Na}^{+}, \mathrm{Mg}^{2+}$ and $\mathrm{Ba}^{2+}$ slightly enhanced the intensity (Figure 7a). Concerning the emission spectra, $\mathrm{Cu}^{2+}$ reduced the fluorescence intensity to $45 \%$ of that observed without the additive. This shows a clear contrast to the results of naphthalimide 1; quenching by $\mathrm{Cu}^{2+}$ was almost complete under the same conditions (Figure 6b) $\mathrm{Li}^{+}, \mathrm{Na}^{+}, \mathrm{Mg}^{2+}$ and $\mathrm{Ba}^{2+}$ did not display any remarkable effects on the emission spectra although they slightly affected the absorption spectra (Figure 7b).
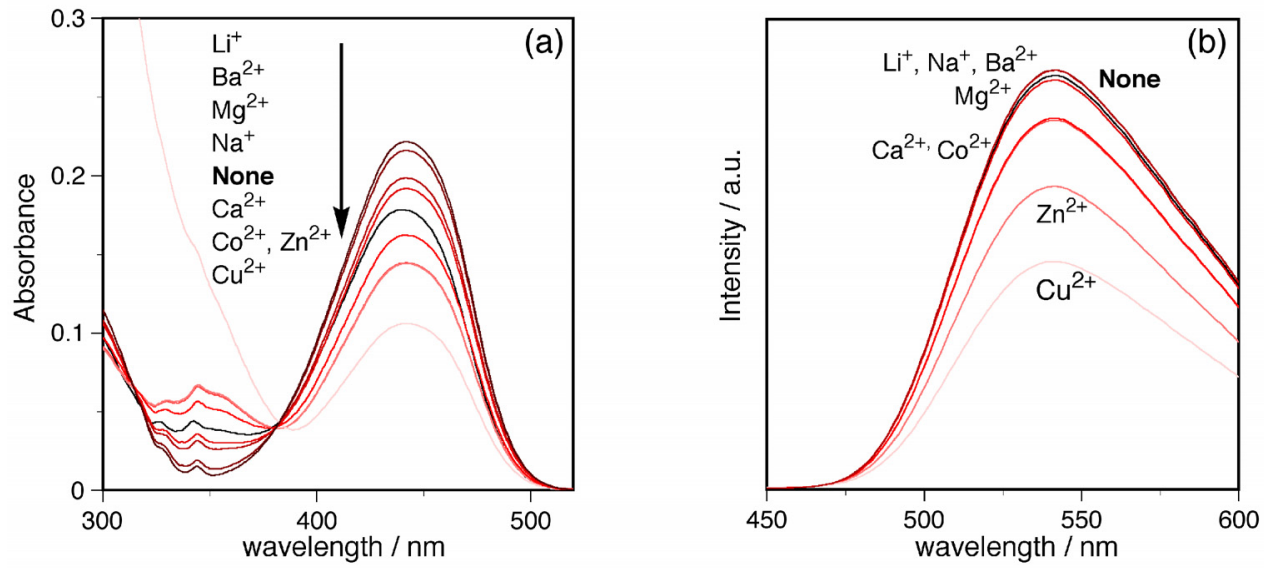

Figure 7. (a) Absorption and (b) fluorescence emission spectra ( $\lambda_{\text {ex }} 384 \mathrm{~nm}$ ) of naphthalimide 2 in the presence of metal cations (10 equiv.) in DMSO. In the absorption spectrum observed after the addition of $\mathrm{Cu}^{2+}$, the absorption band of the metal cation overlapped in the shorter wavelength region $(<370 \mathrm{~nm})$. 
These results indicate that naphthalimides $\mathbf{1}$ and $\mathbf{2}$ were insensitive to metal cations in their neutral amide form $(\mathbf{1}, \mathbf{2}$ in $\mathrm{MeCN})$, in contrast, in their anion form (1', $\mathbf{2}^{-}$in DMSO), they showed a decreased fluorescence intensity as well as suppression of the amide-anion absorption band upon the addition of metal cations. Therefore, it is concluded that on the basis of solvent effects (namely Lewis basicity or donor ability), one can effectively control the sensitivity toward metal cations of the naphthalimides $\mathbf{1}$ and $\mathbf{2}$ as well as their fluorescence color.

The changes in the absorption and fluorescence profiles of the naphthalimides look rather simple (Figures 6,7); the apparent isosbestic points are observed in the absorption spectra and no extra emission band appeared in the fluorescence spectra with the addition of cations. These facts suggest that the spectral properties are modulated by a single factor, e.g., a Lewis acid-base interaction. In order to have insight into the effects of the cations on the spectra, correlations between the observed spectral changes and Lewis acidity of the metal cations are considered as shown in Figure 8. The absorbance changes in the amide-anion band of the naphthalimides 1 $\left(\lambda_{\max } 422 \mathrm{~nm}\right)$ and $2\left(\lambda_{\max } 434 \mathrm{~nm}\right)$ were plotted versus the Fukuzumi's Lewis acidity parameters $^{18}$ of the metal cations (Figure $8 \mathrm{a}$ ). These plots show that the absorbance of the amide anions tended to decrease as the Lewis acidity increased. Furthermore, the fluorescence spectra of the naphthalimides $\mathbf{1}$ and $\mathbf{2}$ were more effectively quenched by the metal cations of stronger Lewis acidity (Figure 8b). Considering that, in DMSO, the absorption and the emission bands of the anions $\mathbf{1}^{-}$and $\mathbf{2}^{-}$possess an ICT character, ${ }^{10}$ it is rational that coordination of a metal cation onto the amide anion suppressed the ICT transitions $\left(\mathbf{1}^{-}-\mathrm{M}^{\mathrm{n}+}\right.$ and $\mathbf{2}^{-}-\mathbf{a}-\mathrm{M}^{\mathrm{n}+}$, Scheme 2) resulting in the decreased absorption and fluorescence intensities.
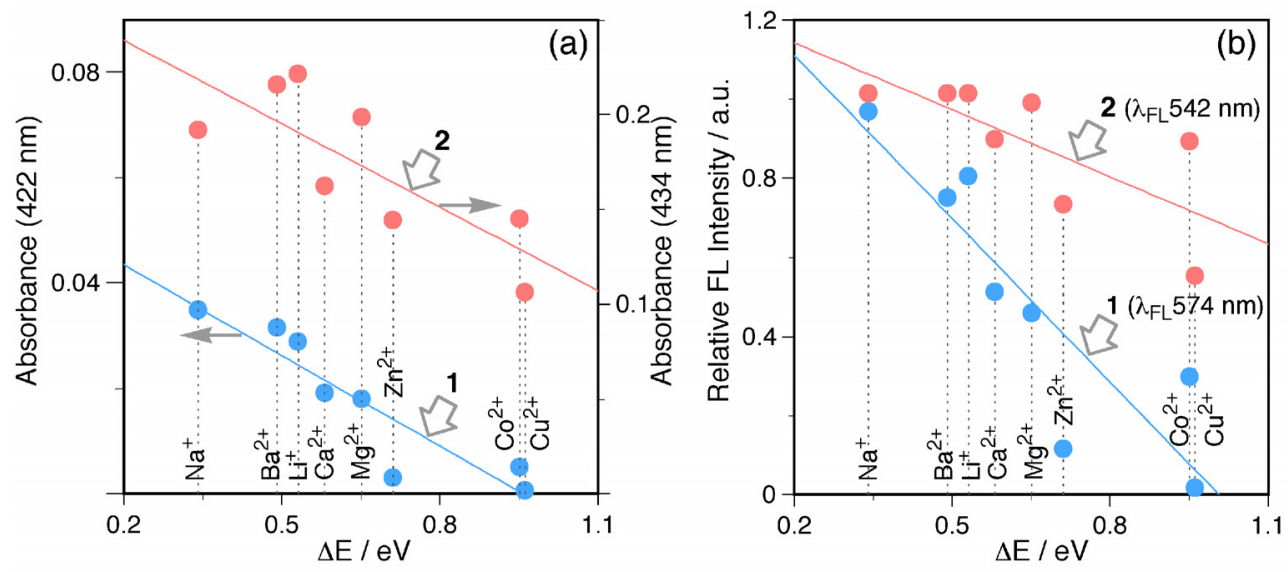

Figure 8. Plots of the absorbance and the relative fluorescence intensity of the naphthalimides $\mathbf{1}$ and $\mathbf{2}$ observed in the presence of metal cations (10 equiv.) versus the Fukuzumi's Lewis acidity parameters $(\Delta \mathrm{E}$, ref. 18$)$ of the metal cations.

(a) Absorbance at $\lambda_{\max }$ vs $\Delta \mathrm{E}: \lambda_{\max } 422 \mathrm{~nm}$ for 1 and $434 \mathrm{~nm}$ for 2.

(b) Relative FL intensity at $\lambda_{\mathrm{FL}}$ vs. $\Delta \mathrm{E}: \lambda_{\mathrm{FL}} 574 \mathrm{~nm}$ for 1 and $542 \mathrm{~nm}$ for 2. 
Naphthalimide 1 showed better correlations between the spectral change and the Lewis acidity compared to those for naphthalimide 2 (Figure 8). As the amide anion and the electronwithdrawing imide part are cross-conjugated in $\mathbf{1}^{-}$, the negative charge may be distributed on the amide and the naphthalene ring (Scheme 2a). On the other hand, for the amide anion 2-, its negative charge can be delocalized to the electron-accepting imide moiety through direct conjugation $\left(2^{-}-\mathbf{b}\right.$, Scheme $\left.2 b\right)$. Due to the resonance contributions, coordination of the imide carbonyls with a metal cation may be more efficient for $\mathbf{2}^{-}$than for $\mathbf{1}^{-}\left(\mathbf{2}^{-}-\mathbf{b}-\mathrm{M}^{\mathrm{n}+}\right.$, Scheme $\left.2 \mathrm{~b}\right)$. The contribution of the complexes $\mathbf{2}^{-}-\mathbf{a}-\mathrm{M}^{\mathrm{n}+}$ and $\mathbf{2}^{-}-\mathbf{b}-\mathrm{M}^{\mathrm{n}+}$ presumably complicates the responses of naphthalimide $\mathbf{2}$ to metal cations compared to those of naphthalimide 1; actually, some alkaline and alkaline earth metal cations enhanced the absorption intensity of 2 (Figure $7 \mathrm{a}$ ). ${ }^{19}$

(a)

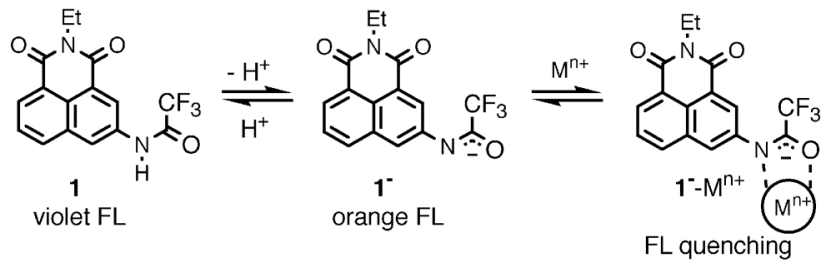

(b)

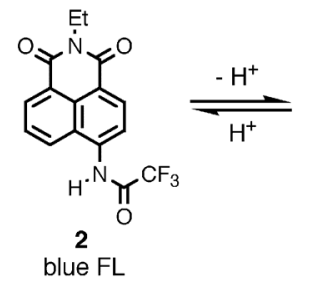

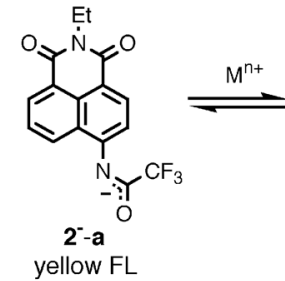

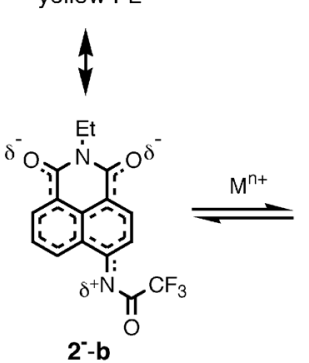

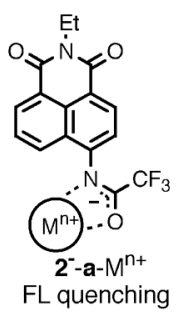

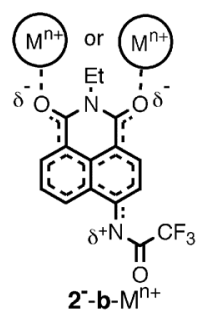

Scheme 2. Modification of the fluorescence properties of $\mathbf{1}$ and $\mathbf{2}$ by solvent and metal cations. FL denotes fluorescence.

Summary. The effects of solvents and metal-cations on the fluorescence spectra of the modified naphthalimides 1 and $\mathbf{2}$ were investigated. In $\mathrm{MeCN}$, the naphthalimides existed in their neutral amide form while, in DMSO, they were deprotonated to form the amide anions (Scheme 1). The fluorescence color of the naphthalimides changed from violet $\sim$ blue (in $\mathrm{MeCN}$ ) to yellow orange (in DMSO) depending on the solvent basicity (Figures 5, 6). The naphthalimides were essentially insensitive to the metal cations in $\mathrm{MeCN}$, whereas in DMSO, they showed a fluorescence response to the metal cations. Therefore, switching of the fluorescence color and the sensitivity to metal cations of the naphthalimides $\mathbf{1}$ and $\mathbf{2}$ can be simultaneously attained, as 
we expected, by changing the solvent. The molecular design of the present solvent-driven functional dyes would provide a basis for a novel multicolor photoluminescent device and would be applicable for the construction of a fluorescent probe sensitive to biologically important ionic species as well as to the environment in which the analyte exists.

\section{Experimental Section}

General Procedures. The ${ }^{1} \mathrm{H}(300 \mathrm{MHz})$ and ${ }^{13} \mathrm{C}(150 \mathrm{MHz})$ NMR spectra were collected using VARIAN Mercury 300 and INOVE AS600 spectrophotometers, respectively. The fluorescence spectra were measured at $25{ }^{\circ} \mathrm{C}$ by a HITACHI F2500 spectrofluorophotometer with a 1-cm path-length quartz cell. The spectra were corrected against the instrumental response using rohdamine B. Spectroscopic-grade solvents were used for the absorption and the fluorescence measurements as received. The perchlorates of $\mathrm{Li}^{+}, \mathrm{Na}^{+}, \mathrm{K}^{+}, \mathrm{Mg}^{2+}$ and triflates of $\mathrm{Ca}^{2+}, \mathrm{Ba}^{2+}$, $\mathrm{Co}^{2+}, \mathrm{Cu}^{2+}, \mathrm{Zn}^{2+}$ were used as the metal-cation sources. 3-Amino- $N$-ethyl-1,8-naphthalimide was prepared by reduction of 3-nitro- $N$-ethyl-1,8-naphthalimide with $10 \% \mathrm{Pd} / \mathrm{C}$ in the presence of formic acid in the yield of $89 \%$; its spectral features were consistent with those of reported ones. $^{20} 4$-Amino- $N$-ethyl-1,8-naphthalimide was prepared by $N$-ethylation of the imide miety of 4-amino-1,8-naphthalimide with iodoethane in the presence of sodium hydride in the yield of $33 \%$, and its spectral data were identical with reported ones. ${ }^{21}$

$N$-Ethyl-3-trifluoroacetylamino-1,8-naphthalimide (1). To a mixture of 3-amino- $N$-ethyl-1,8naphthalimide (961 mg, $4 \mathrm{mmol}$ ) and sodium carbonate $(212 \mathrm{mg}, 2 \mathrm{mmol})$ in $60 \mathrm{ml}$ of 1,4dioxane was dropwise added a solution of trifluoroacetic anhydride $(1.26 \mathrm{~g}, 6 \mathrm{mmol})$ in $10 \mathrm{ml}$ of 1,4-dioxane. The mixture was then stirred at room temperature for $15 \mathrm{~min}$. The salts were filtered off and the filtrate was concentrated under reduced pressure. The residue was chromatographed on silica gel $($ Hexane/AcOEt $=2 / 1)$ to give naphthalimide 1 in a quantitative yield $(1.34 \mathrm{~g}, 99 \%)$. Recrystallization from a mixture of hexane/AcOEt gave fine colorless needles. Colorless needles, mp 261-263 ${ }^{\circ} \mathrm{C} .{ }^{1} \mathrm{H}$ NMR (300 MHz, Acetone-d $\left.{ }_{6}\right) \delta=10.7$ (br, 1H), 8.85 (d, 1H, J 2.5 $\mathrm{Hz}), 8.78$ (d, 1H, J 2.5 Hz), 8.51 (dd, 1H, J 7.3, 1.0 Hz), 8.42 (dd, 1H, J 8.3, $1.0 \mathrm{~Hz}$ ), 7.89 (dd, $1 \mathrm{H}, J 8.3,7.3 \mathrm{~Hz}), 4.17(\mathrm{q}, 2 \mathrm{H}, J 7.1 \mathrm{~Hz}), 1.28(\mathrm{t}, 3 \mathrm{H}, J 7.1 \mathrm{~Hz}) .{ }^{13} \mathrm{C}$ NMR $(150 \mathrm{MHz}$, Acetone$\left.\mathrm{d}_{6}\right) \delta=163.9,163.6,156.1\left(\mathrm{q}, J_{\mathrm{CF}}=38.0 \mathrm{~Hz}\right), 136.1,134.6,133.0,130.9,128.7,126.4,125.0$, $124.7,124.2,123.5,116.8\left(\mathrm{q}, J_{\mathrm{CF}}=287.9 \mathrm{~Hz}\right), 35.8,13.5$. IR $(\mathrm{KBr}) v_{\max } 1736,1696 \mathrm{~cm}^{-1}$. UVVIS, see Figure 1a. Anal. Found: C, 57.51; H, 3.53; N, 8.39\%. Calcd for $\mathrm{C}_{19} \mathrm{H}_{27} \mathrm{~N}_{2} \mathrm{O}$ : C, 57.15; $\mathrm{H}, 3.30 ; \mathrm{N}, 8.33 \%$.

$\mathrm{N}$-Ethyl-4-trifluoroacetylamino-1,8-naphthalimide (2). Compound 2 was prepared by the trifluoroacetylation of 4-amino- $N$-ethyl-1,8-naphthalimide according to the above procedure in a $74 \%$ yield. Colorless needles, mp 247-248 ${ }^{\circ} \mathrm{C} .{ }^{1} \mathrm{H}$ NMR $\left(300 \mathrm{MHz}\right.$, acetone- $\left.\mathrm{d}_{6}\right) \delta=10.8$ (br, $1 \mathrm{H}), 8.60(\mathrm{~d}, 2 \mathrm{H}, J 7.8 \mathrm{~Hz}), 8.59(\mathrm{dd}, 1 \mathrm{H}, J 7.8,1.2 \mathrm{~Hz}) 8.51(\mathrm{dd}, 1 \mathrm{H}, J 8.7,1.2 \mathrm{~Hz}), 8.11(\mathrm{~d}, 1 \mathrm{H}$, $J 7.8 \mathrm{~Hz}), 7.92(\mathrm{dd}, 1 \mathrm{H}, J 8.7,7.2 \mathrm{~Hz}), 4.17$ (q, 2H, $J 7.2 \mathrm{~Hz}), 1.29$ (t, 3H $J 7.2 \mathrm{~Hz}) .{ }^{13} \mathrm{C}$ NMR 
$\left(150 \mathrm{MHz}\right.$, Acetone- $\left.\mathrm{d}_{6}\right) \delta=164.1,163.6,157.1$ (q, $\left.J_{\mathrm{CF}}=37.8 \mathrm{~Hz}\right), 137.5,131.9,131.4,129.6$, $129.5,128.1,127.4,124.6,124.2,122.6,117.1$ (q, $\left.J_{\mathrm{CF}}=286.5 \mathrm{~Hz}\right), 35.8,13.5$. IR $(\mathrm{KBr}) v_{\max }$ $1717,1659 \mathrm{~cm}^{-1}$. UV-VIS, see Figure 2a. Anal. Found: C, 56.88; H, 3.54; N, 8.21\%. Calcd for $\mathrm{C}_{19} \mathrm{H}_{27} \mathrm{~N}_{2} \mathrm{O}$ : C, 57.15; H, 3.30; N, 8.33\%.

\section{Acknowledgements}

The authors are grateful to the SC-NMR Laboratory and the Advanced Science Research Center of Okayama University for the service of ${ }^{1} \mathrm{H}$ and ${ }^{13} \mathrm{C}$ NMR spectral measurements.

\section{References and Footnotes}

1. (a) Löhr, H.-G.; Vögtle, F. Acc. Chem. Res. 1985, 18, 65. (b) Vögtle, F. Supramolecular Chemistry (Japanese translated edition); Maruzene-Wiley: Tokyo, 1995.

2. (a) de Silva, A. P.; Gunaratne, H. Q. N.; Gunnlaugsson, T.; Huxley, A. J. M.; McCoy, C. P.; Rademacher, J. T.; Rice, T. E. Chem. Rev. 1997, 97, 1515. (b) de Silva, A. P.; Fox, D. B.; Huxley, A. J. M.; Moody, T. S. Coord. Chem. Rev. 2000, 205, 41.

3. (a) Okamoto, H.; Owari, M.; Kimura, M.; Satake, K. Tetrahedron Lett. 2001, 42, 7453. (b) Okamoto, H.; Kimura, M. Luminescence 2004, 19, 169. (c) Okamoto, H.; Kimura, M. Chem. Lett. 2005, 1452.

4. (a) Nakai, S.; Yasui, M.; Nakazato, M.; Iwasaki, F.; Maki, S.; Niwa, H.; Ohashi, M.; Hirano, T. Bull. Chem. Soc. Jpn. 2003, 76, 2361. (b) Sekiguchi, T.; Maki, S.; Niwa, H.; Ikeda, H.; Hirano, T. Tetrahedron Lett. 2004, 45, 1065.

5. Tanaka, K.; Kumagai, T.; Aoki, H.; Deguchi, M.; Iwata, S. J. Org. Chem. 2001, 66, 7328.

6. Okamoto, H.; Kohno, M.; Satake, K.; Kimura, M. Bull. Chem. Soc. Jpn. 2005, 78, 2180.

7. (a) Reichardt, C. Chem. Rev. 1994, 94, 2319. (b) Saroja, G.; Soujanya, T.; Ramachandram, B.; Samanta, A. J. Fluorescence 1998, 8, 405.

8. Karmakar, R.; Samanta, A. J. Am. Chem. Soc. 2001, 123, 3809.

9. Alexiou, M. S.; Tychopoulos, V.; Ghorbanian, S; Tyman, J. H. P.; Brown, R. G.; Brittain, P. I. J. Chem. Soc. Perkin Trans. 2 1990, 837.

10. Liu, B.; Tian, H. J. Mater. Chem. 2005, 15, 2681.

11. (a) Esteban-Gómez, D.; Fabbrizzi, L.; Licchelli, M.; Sacchi, D. J. Mater. Chem. 2005, 15, 2670. (b) Esteban-Gómez, D.; Fabbrizzi, L.; Licchelli, M.; J. Org. Chem. 2005, 70, 5717.

12. (a) Gunnlaugsson, T.; Kruger, P. E.; Lee, T. C.; Parkesh, R.; Pfeffer, F. M.; Hussey, G. M. Tetrahedron Lett. 2003, 44, 6575. (b) Gunnlaugsson, T.; Kruger, P. E.; Jensen, P.; Pfeffer, F. M.; Hussey, G. M. Tetrahedron Lett. 2003, 44, 8909. (c) Pfeffer, F. M.; Buschgens, A. M.; Barnett, N. W.; Gunnlaugsson, T.; Kruger, P. E. Tetrahedron Lett. 2005, 46, 6579.

13. Reichardt, C. Solvents and Solvent Effects in Organic Chemistry 2nd Ed.; VCH: Wienheim, 1988. 
14. Persson, I. Pure. Appl. Chem. 1986, 58, 1153.

15. For the ${ }^{1} \mathrm{H}$ NMR spectra of the naphthalimide $\mathbf{1}$ and $\mathbf{2}$, the signal of the amide proton observed at 9.6-9.8 ppm in $\mathrm{MeCN}-\mathrm{d}_{3}$ ' whereas the signal remarkably shifted to down-field $\sim 11.9 \mathrm{ppm}$. These observations suggest that, in DMSO, the amide proton is more acidic than in $\mathrm{MeCN}$ and the amide anions $\mathbf{1}^{-}$and $\mathbf{2}^{-}$were formed readily.

16. Boiocchi, M.; Boca, L. D.; Gómez, D. E.; Fabbrizzi, L.; Licchelli, M.; Monzani, E. J. Am. Chem. Soc. 2004, 126, 16507.

17. Recently, a white-light-emitting material in which RGB emitters are assembled in one molecule have been reported. Coppo, P.; Duati, M.; Kozhevnikov, V. N.; Hofstraat, J. W.; De Cola, L. Angew. Chem, Int. Ed. 2005, 44, 1806.

18. (a) Fukuzumi, S.; Ohkubo, K. J. Am. Chem. Soc. 2002, 124, 10270. (b) Ohkubo, K.; Menon, S. C.; Orita, A.;Otera, J.; Fikuzumi, S. J. Org. Chem. 2003, 68, 4720.

19. Bourson, J.; Pouget, J.; Valeur, B. J. Phys. Chem. 1993, 97, 4552.

20. Pardo, A.; Martin, E.; Poyato, J. M. L.; Camacho, J. J.; Brana, M. F.; Castellano, J. M. J. Photochem. Photobiol., A: Chem. 1987, 41, 69.

21. Khosravi, A.; Moradian, S.; Gharanjig, K.; Taromi, A. F. Dyes and Pigments 2006, 69, 79. 